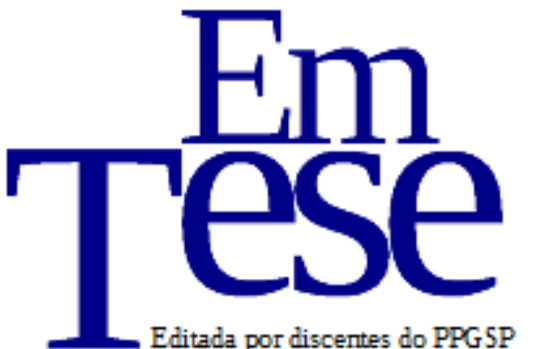

UFSC

PPG SP PROG RAMA DE

POS-GRADUAÇÃO EM

Sociologia Política

V. 15, n. 2 p. 01, Julho, 2018.

DOI: http://dx.doi.org/10.5007/1806-5023.2018v15n2p85

\title{
De Heidelberg a Frankfurt: \\ Norbert Elias no círculo de "mandarins" alemães pós 1920 "
}

Débora Previatti ${ }^{2}$

Resumo: Este artigo tem como foco a passagem de Norbert Elias por Heidelberg e Frankfurt, a fim de analisar de que modo ela repercutiu sobre a formação, a trajetória e algumas produções desse autor. Tomando como ponto de partida a sua obra autobiográfica, a análise contemplou algumas produções nacionais e internacionais acerca de sua trajetória intelectual, pessoal e institucional. A rede de relações na qual Elias esteve engendrado foi decisiva para a sua formação sociológica, para a elaboração de suas principais obras e também para o seu reconhecimento, mesmo que tardio. Para além das particularidades de Elias, elementos comuns encontrados nas narrativas de "mandarins" alemães permitem detectar um relativo "padrão de pensamento" pós 1920, em razão do momento de efervescência weberiana, do nazismo e do clima de "crise da cultura" alemã.

Palavras-chave: Norbert Elias, Círculos de Intelectuais, Max Weber, Pensamento Social Alemão.

\section{From Heidelberg to Frankfurt: \\ Norbert Elias in the German "mandarins" circle post 1920}

\begin{abstract}
This article focuses on the passage of Norbert Elias by Heidelberg and Frankfurt, in order to analyze how it impacted on the formation, the trajectory and some productions of this author. Taking his autobiographical work as a starting point, we have analysed some national and international productions about his intellectual, personal and institutional trajectory. The network of relationships in which Elias was engendered was decisive for his sociological formation, for the elaboration of his main works and also for his recognition, even if late. In addition to the particularities of Elias, common elements found in the German "mandarins" narratives allow us to detect a relative "pattern of thought" post 1920 due to weberian euphoric momentum, nazism and german "crisis of culture" climate.
\end{abstract}

Keywords: Norbert Elias, Intellectuals Circles, Max Weber, German Social Thought.

\footnotetext{
1 Esta obra está licenciada com uma Licença Creative Commons Atribuição 4.0 Internacional.

${ }^{2}$ Doutoranda em Sociologia Política pela Universidade Federal de Santa Catarina (UFSC), com estágio de doutoramento pela École des Hautes Études em Sciences Sociales de Paris. Contato: deborapreviatti@gmail.com
} 


\section{Introdução}

Conforme analisou Ringer (2004), determinados padrões de pensamento podem ser reconhecidos em obras de intelectuais que estiveram inscritos em um mesmo contexto espacial e temporal. Dessa forma, os textos escritos por esses indivíduos podem ser vistos como integrados a um "conjunto textual" mais amplo que, por sua vez, insere-se em um contexto intelectual ou tradição específicos. Compreender uma obra por essa dimensão de análise nos faz enxergar para além da escrita, com a qual podemos alcançar uma clareza maior a respeito do pensamento de um autor, o qual estava necessariamente situado em um determinado contexto social.

Em 1924, quatro anos após o falecimento de Max Weber, Norbert Elias chegou pela primeira vez na cidade de Heidelberg, que consistia, na época, em uma espécie de "Meca da Sociologia" (ELIAS, 2001a). Com formação, até aquele instante, apenas em filosofia e medicina, o jovem Elias percebeu que, para vir a se consagrar e construir a sua carreira entre os sociólogos, ele deveria fazer parte daquele círculo de intelectuais. No período de sua chegada, os intelectuais estavam especialmente ocupados em realizar profundos debates acerca da teoria weberiana e esta era encontrada em grande medida nas produções dos indivíduos inseridos naquele contexto e de seus sucessores (ELIAS, 2001a). Após o período em Heidelberg, Elias seguiu a Frankfurt, acompanhando Karl Mannheim. A passagem do autor por ambas as cidades caracterizou o início de sua formação sociológica e repercutiu de forma decisiva na escrita de suas duas principais obras, "A Sociedade de Corte" e "O Processo Civilizador". Caracterizou, portanto, uma fase importante de sua biografia, a qual será enfatizada no presente artigo ${ }^{3}$.

Na primeira seção do artigo, argumentamos sobre alguns aspectos metodológicos considerados importantes para a análise aqui empreendida. Em seguida, em “Os 'mandarins' da sociologia alemã”, apresentamos algumas características compartilhadas pelo grupo de intelectuais contemporâneos a Norbert Elias na Alemanha pós 1920, ano de falecimento de Max Weber. Recorremos posteriormente ao cenário social no qual Elias foi apresentado ao pensamento weberiano e à família Weber, quando teve seus primeiros ensinamentos de sociologia e a sua primeira entrada no círculo dos "mandarins" da sociologia alemã. Tratamos aqui sobre a formação de Elias na cidade de Heidelberg que, na época de sua chegada,

\footnotetext{
${ }^{3}$ Korte (1998) dividiu a trajetória de Elias em três fases: a. Juventude e estudos em Breslau; b. O tempo em Heidelberg e em Frankfurt e, por fim; c. O exílio na Inglaterra. A última é considerada por alguns autores, como Lacroix (1997) e Rotman (2005), por motivos que diferem dos que apontamos no presente artigo, como sendo igualmente um momento-chave da biografia de Elias.
} 
reverberava intensamente a teoria de Max Weber, principalmente após o falecimento desse autor. Enfatizamos, também, nesse contexto, a centralidade de um espaço físico em particular para aquele círculo de intelectuais e que era frequentado por Elias, o salão de Marianne Weber. Por fim, o artigo segue com uma discussão sobre a relação de Elias com Alfred Weber, irmão de Max Weber, culminando na sua saída de Heidelberg para acompanhar o seu orientador e amigo na época, Karl Mannheim.

\section{Metodologia}

Uma obra central para a presente análise foi a obra autobiográfica intitulada "Norbert Elias por ele mesmo", por meio da qual se tem acesso a uma história de vida narrada pelo próprio autor, além de uma entrevista biográfica, realizada por AJ. Heerma van Voss e A. van Stolk (ELIAS, 2001a). Apesar desse fato, consideramos a noção de que a narrativa de vida de um indivíduo não corresponde à sua história de vida, pois na medida em que nela o entrevistado procura dar sentido à sua fala, tende a colocá-la em uma ordem cronológica, como se as trajetórias de vida fossem retilíneas, quando isso se trata, na realidade, de uma “ilusão biográfica” (BOURDIEU, 1996).

Levamos em consideração igualmente o fato de que a narrativa construída por Elias sobre a sua própria história de vida visava, sobretudo, o seu posicionamento enquanto autor de uma teoria social própria. Apesar disso, acreditamos que muitos elementos presentes ali podem ser relevantes justamente para compreender os seus posicionamentos frente a outros intelectuais, aos seus contemporâneos mas também àqueles que o antecederam, incluindo Max Weber. Tais informações, por meio de uma análise crítica, serviram como fontes da pesquisa.

Foram investigadas ainda algumas produções nacionais e internacionais de comentadores que abordassem sobre a trajetória intelectual, pessoal e institucional de Norbert Elias, incluindo especialmente os materiais que possuíam como foco a sua passagem por Heidelberg e/ou Frankfurt.

Em todos os casos, foram consideradas as condições de produção das fontes, visando compreender em que medida os elementos dos materiais coletados remetiam às propriedades sociais dos contextos analisados (MICELI, 2001). As posições sociais das fontes também foram analisadas, visto que estas são importantes para situar o ponto de vista a partir do qual são elaboradas as informações e as representações dessas fontes (COMBESSIE, 2004). 
Além disso, o presente trabalho tem como pressuposto a noção de que, por meio do esclarecimento de características comuns àqueles contextos, que abrigavam um determinado círculo de intelectuais, submetidos a conjunturas políticas e culturais específicas, temos a possibilidade de compreender de modo mais aprofundado as obras de Elias, cometendo-se, assim, menos anacronismos. Acreditamos aqui que uma obra que é lida deslocada de seu contexto de produção não permite captar algumas motivações e intenções de um autor, muito menos as suas críticas, os seus diálogos e outros de seus posicionamentos frente a autores que lhe são contemporâneos ou predecessores. Dessa forma, conhecer tais informações permitem situar Elias em seu tempo, no círculo de intelectuais onde esteve engendrado, em uma trama de inter-relações.

\section{Resultados e Discussão}

\subsection{Os "mandarins" da sociologia alemã}

Em alusão aos burocratas eruditos da China imperial, Simone de Beauvoir (1983) emprestou o termo "mandarins" para explicar o círculo de intelectuais parisienses do final da Segunda Guerra Mundial, às vésperas da Guerra Fria. Muito mais do que um romance, a consagrada obra de Beauvoir disseca a vida pessoal de cada um dos membros desse círculo de pensadores e nos mostra como a produção intelectual dos mesmos esteve intrinsecamente relacionada e condicionada ao contexto social no qual todos eles estavam inseridos.

O termo "mandarim" em Ringer (2000), ao abordar sobre os "mandarins alemães", refere-se às classes "cultas" alemãs de modo geral, mais especificamente aos professores universitários. De acordo com o autor, a elite cultural teve um papel de extrema importância para a sociedade alemã moderna, o que permitiu formular uma nova história intelectual alemã.

Tal contexto tem importância na medida em que é percebido que desvendar uma dada história intelectual e cultural não envolve apenas conhecer a história das ideias (o estudo do pensamento sistemático) a ela relacionada. Além da história das ideias, segundo Pontes (1997), a partir da definição de Robert Darnton (1990), a história intelectual e cultural inclui:

a história intelectual propriamente dita (o estudo do pensamento informal, dos climas de opinião, dos movimentos literários), a história social das idéias (o estudo da ideologia e da difusão das idéias) e a história cultural (o estudo da cultura no sentido antropológico, incluindo visões de mundo e mentalités coletivas) (DARNTON, 1990, p. 188 apud PONTES, 1997). 
Mesmo quando o objetivo é apenas o de traçar uma história das ideias, já se sabe há algum tempo da importância do contextualismo linguístico, por meio do debate proposto principalmente por Quentin Skinner (1969), mas também por John Pocock (1962) e John Dunn (1968). Mais uma vez, com esses autores, encontramos a importância da leitura do texto de um determinado autor, seja ele clássico ou contemporâneo, inserindo-o em seu tempo. Como propôs Dunn (1968, p. 86), "tanto a especificidade histórica quanto a sofísticação filosófica serão mais bem alcançadas se ambas forem perseguidas em conjunto". Segundo Silva (2010):

\begin{abstract}
Ao mesmo tempo que argumentava contra a suposição de infalível "coerência" dos grandes pensadores, Skinner criticava o que considerava uma vaga noção de "influência", mediante a qual se compunha um tipo de narrativa em que as grandes ideias de grandes autores explicavam-se pela influência recebida de outras grandes ideias de outros grandes autores (SILVA, 2010, p. 303).
\end{abstract}

Nesse sentido, tentamos aqui nos aproximar mais do que Robert Darnton denominou de história intelectual e cultural (PONTES, 1997). Nesse debate tem importância a contribuição de Ringer (2004). Em sua obra "A metodologia de Max Weber”, o autor versa sobre a análise de Wilhelm Dilthey a respeito da existência de "estruturas" intelectuais ou "padrões de pensamento". Ringer (2004) conta que Dilthey defendia que, ao captarmos o raciocínio geral de certa linha de pensamento, podemos compreender os "produtos mentais" de cada um dos autores relacionados. Isso ocorreria devido ao fato de o texto estar integrado a um "conjunto textual" que, por sua vez, insere-se um determinado contexto intelectual ou tradição. Outrossim, entender uma obra por essa dimensão de análise nos faz enxergar para além da escrita, com uma clareza maior a respeito do pensamento de um autor, inscrito em um contexto social específico.

Assim, o contexto intelectual no qual Norbert Elias esteve engendrado, do mesmo modo que a sua origem social e a sua trajetória de vida ${ }^{4}$, deve explicar muitos elementos presentes em suas produções. Nesse sentido, o enfoque dado aqui é de um recorte temporal e espacial específico, o do momento da inserção de Elias no círculo intelectual alemão de Heidelberg, onde obteve a maior parte de sua formação propriamente sociológica, além de sua partida posterior a Frankfurt. A produção das suas obras reverberou, em grande medida, temas, ideias, debates, confluências e contraposições derivados desses contextos intelectuais,

\footnotetext{
${ }^{4}$ Para um maior aprofundamento sobre o impacto da origem social e da trajetória de vida de Norbert Elias sobre suas obras, ver Elias (2001a).
} 
históricos e sociais. Nesse sentido, muitos posicionamentos de Norbert Elias podem ser melhor compreendidos quando se investiga a fundo com que ideias de quais autores ele dialoga, ou ele se distancia e critica, justamente para denotar uma posição.

Ringer (2000), em sua obra "O declínio dos mandarins alemães: a comunidade acadêmica alemã, 1890-1933”, analisou profundamente como a produção intelectual alemã estava, de modo geral, amplamente relacionada ao contexto social e político da sociedade alemã da época. Fatores como a democratização da universidade, a crise da cultura humanística na era tecnológica e o surgimento do nazismo tiveram forte impacto sobre as produções acadêmicas do período. Havia, portanto, uma íntima relação entre a política e a vida intelectual alemã da época.

Conforme Ringer (2000), predominava um clima de "crise da cultura" na comunidade alemã no período em que Elias chegou a Heidelberg. Por volta de 1890, iniciaram manifestações individuais de acadêmicos alemães sobre uma preocupação com o ensino e com a vida cultural alemães. Tais inquietações perduraram até a década de 1930.

Foi na década de 1920 que passou a ser consensual a crença de que uma "crise da cultura" era iminente na Alemanha. A preocupação era, sobretudo, com um possível declínio da vitalidade das tradições intelectuais alemãs, que se acreditava estarem perdendo o seu sentido e a sua importância. Os acadêmicos indagavam-se sobre a possibilidade de vir sendo extinto o seu status de "líderes espirituais" nas universidades e de a cultura "mandarim" vir a ser abandonada. Alfred Weber (1918) chegou a escrever um artigo no qual ele questionava a respeito de os chamados "líderes intelectuais e espirituais" possuírem menor influência em sua época do que naquela do início do século XIX na Alemanha.

A crise cultural, pela qual acreditavam passar os "mandarins" alemães, repercutiu também sobre as suas obras. Os autores passavam a redefinir em seus escritos aquelas representações que tinham sobre eles próprios. Os seus então atacados valores tradicionais passavam agora por uma revisão, manifestada por meio de uma espécie de auto-análise e de uma história intelectual que era agora contada pelos próprios "mandarins". A respeito de tais características comuns presentes nas produções desses indivíduos, que contribuíam para a construção de um "legado mandarim”, Ringer (2000) afirma que:

Algumas foram feitas com bastante espírito crítico; a maioria, porém, negligenciou as implicações sociais das idéias que descreveram. Foi aí que os analistas posteriores tiveram de ajustar o equilíbrio. Desde a década de 1930, muitos desses comentaristas mais recentes eram eruditos alemães expatriados. Alguns haviam estudado, inicialmente, com representantes da ala mais crítica de uma geração acadêmica alemã mais antiga ou foram de 
alguma forma influenciados por ela. Assim, os trabalhos de Hans Gerth e Hans Rosenberg, de Koppel S. Pinson, Hajo Holborn, Leonard Krieger e W. H. Brufor são conseqüências e, ocasionalmente, correções dos escritos de Otto Hintze e Max Weber, de Ernst Troeltsch, Friedrich Meinecke e Eduard Spranger. Quando lemos as obras dessas duas gerações de escritores, e mais alguns títulos de Wilhelm Windelband e Karl Jaspers, de Norbert Elias e Wilhelm Roessler, chegamos a uma visão única e internamente coerente do legado mandarim. Não se trata de uma visão acrítica, muito pelo contrário; mas continua sendo uma análise como que feita "de dentro". Sua linguagem e a posição a partir da qual se remonta às fontes do pensamento alemão moderno ainda são, de certo modo, aquelas das décadas de 1890 e 1920 (RINGER, 2000, p. 92, grifo nosso).

Tão ou mais importante que saber que tal crença existia no período e que, portanto, reverberava um determinado padrão de pensamento compartilhado naquele círculo de intelectuais, inscrito em um mesmo momento histórico e espacial, era compreender que aquelas obras encontravam-se também, sobretudo, sob o efeito impactante do nazismo. Provavelmente, era muito difícil para aqueles autores permanecerem indiferentes em relação ao nazismo em suas produções. Em especial na vida de Norbert Elias, o nazismo repercutiu fortemente em sua visão de mundo e, consequentemente, em suas produções, pela sua inevitável aproximação a ele (ELIAS, 2001a).

Elias (2001a) narra diferentes momentos de sua trajetória pessoal e profissional que teriam sido impactados de diferentes maneiras pelo nazismo. Alemão e judeu, desde criança Norbert Elias foi vítima de antissemitismo; posteriormente, em outra fase da vida perdeu os seus pais durante a Segunda Guerra (sua mãe foi assassinada em Auschwitz), além do fato de ter atuado no front da Primeira Guerra e em 1939 ter sido exilado por oito meses em um campo de refugiados na Ilha de Mann. Segundo Heinich (2001), tais dificuldades tiveram impactos diretos sobre as obras de Elias, dentre eles, o fato de sua tese apresentada em 1933 só ter sido publicada mais de trinta anos depois, além de outras complicações, como aquelas referentes à linguagem de publicação das obras, as quais o acompanharam até praticamente o fim de sua vida.

Dessa forma, tomar conhecimento de todo o impacto que o nazismo apresentou na visão de mundo de Norbert Elias e compreender a posição e a repercussão do autor no processo de formação do legado "mandarim" da sociologia alemã ${ }^{5}$ podem ser ferramentas auxiliares importantes para uma compreensão mais aprofundada de suas produções.

\footnotetext{
${ }^{5}$ A obra de Joly (2012) pode ser útil a uma análise mais aprofundada sobre este assunto, ao analisar a trajetória de Elias até o seu reconhecimento tardio pela comunidade acadêmica.
} 


\subsection{Elias e a "Meca da Sociologia": o tempo em Heidelberg}

A sociologia gozava de um status muito elevado na Universidade de Heidelberg, muito por causa da lembrança da figura de Max Weber, quando Elias chegou a essa cidade. A relação teórica e/ou pessoal de Norbert Elias com a maioria dos sociólogos que impactaram sobre as suas obras - como Georg Simmel, Karl Mannheim, Max Weber e Alfred Weber, entre outros - iniciou ou foi aprofundada em Heidelberg ${ }^{6}$. Com a efervescência teórica que pairava em Heidelberg na época, houve uma congregação de uma imensidão de intelectuais ${ }^{7}$. Elias (2001a) conta que a sua iniciação ao pensamento sociológico se desenvolveu principalmente, devido à sua ida para a cidade universitária, a partir de seu contato com Jaspers, quem o introduziu à teoria de Max Weber. Até aquele momento ele vinha se dedicando a estudos de caráter filosófico e de medicina, e não possuía conhecimentos de sociologia.

Norbert Elias permaneceu em Heidelberg no período de 1924 a 1930. Elias teria chegado em Heidelberg apenas quatro anos após o falecimento de Max Weber, para seguir a sua almejada carreira acadêmica. Por muito pouco, não foi seu contemporâneo, mas chegou no meio do círculo e espírito weberianos (BUCHOLC, 2013).

Elias (2001a) narra que foi influenciado por todo o ambiente que era considerado naquele momento a "Meca da Sociologia", a universidade de Heidelberg. Nesse período, esteve muito próximo à família de Max Weber. Em sua obra autobiográfica, Elias descreve a respeito de sua aproximação à família Weber, não apenas por meio de Alfred Weber (irmão de Max Weber, tendo sido o seu primeiro orientador na referida universidade), como também de Marianne Weber, esposa de Max Weber.

O grande Max Weber morrera, é verdade, mas sua viúva ainda vivia, e seu irmão Alfred igualmente, ele também professor de sociologia. De maneira geral, a Alemanha já tinha nessa época uma tradição sociológica bastante respeitável. (...) O florescimento da sociologia começou portanto desde a época imperial, mas acentuou-se de fato apenas depois de 1918 (ELIAS, 2001a, p. 44).

\footnotetext{
${ }^{6}$ Cf. Krieken (2001), Elias esteve em Heidelberg no mesmo período também que Talcott Parsons. É interessante notar que, apesar disso, Parsons não é mencionado por Elias (2001a), em sua obra autobiográfica.

${ }^{7}$ Para um maior aprofundamento sobre a importância de Heidelberg na reunião de intelectuais recomenda-se a leitura da obra de Treiber e Sauerland (1995).
} 
Após a morte de Max Weber em 1920, iniciaram-se profundos debates com o objetivo de compreender a sua teoria no círculo de intelectuais alemão. Como consequência disso, a teoria weberiana passou a estar presente não somente nesses debates, mas principalmente em diferentes obras que foram produzidas, no mesmo período e em momentos posteriores, por autores inscritos naquele contexto, dentre eles o próprio Norbert Elias. O ano foi narrado por Elias (2001a) e por outros sociólogos como um marco histórico, que teria caracterizado o momento subsequente, de ampla repercussão em e ao lado de outras grandes obras produzidas no círculo intelectual alemão daquele período, as quais marcaram também, em certa medida, toda a produção sociológica posterior. Nesse cenário, Elias (2001a) conta que nos anos 1920:

\begin{abstract}
Weber ainda estava longe de se destacar do grupo dos especialistas alemães em ciências sociais, ao passo que atualmente, com o recuo do tempo, ele é reconhecido graças à triagem silenciosamente efetuada pelas gerações seguintes. Inúmeros representantes da velha guarda cujas obras gozavam de notoriedade não muito inferior - homens como Tönnies, Sombart, Scheler e Franz Oppenheimer - ainda estavam vivos. As obras de Troeltsch, assim como as de Georg Simmel, faziam parte da bagagem cultural indispensável para um sociólogo, e iniciei o seu estudo, encorajado pela atmosfera que reinava em Heidelberg. No pano de fundo, como sempre, discreto e eloqüente, havia o personagem imponente de Karl Marx. Os debates sociológicos giravam bastante em torno dele, não importava o que se dissesse (ELIAS, 2001a, p. 104).
\end{abstract}

Desde o princípio de sua carreira acadêmica, Elias já entrou no "mundo" de Max Weber - estudando sociologia em Heidelberg, participando das reuniões no salão de Marianne Weber, sendo orientado por Alfred Weber. Apesar disso, Elias não veio a se tornar um "weberiano". Devido ao ambiente intelectual de Heidelberg, era quase impossível que nas suas obras não emergissem temas weberianos. Entretanto, Elias formulou as suas próprias ideias, contribuindo posteriormente não só para complementar Weber, como também para, em certa medida, corrigir aspectos unilaterais de sua teoria. Apesar disso, ao tentar corrigi-lo, as formulações de Elias podem ter envolvido outras formas de unilateralidade, como, por exemplo, em torno da questão da individualização (BREUER, 1994).

Foi também em Heidelberg que a obra eliasiana "A Sociedade de Corte", primeira e uma de suas principais, foi planejada e teve seus escritos iniciais. Em 1925, Elias havia sido aceito por Alfred Weber na Universidade de Heidelberg e conseguido uma cadeira com o trabalho "Die Bedeutung der Florentiner Gesellschaft und Kultur für die Entstehung der Wissenschaft” (“A importância da Sociedade e da Cultura Florentina para o Desenvolvimento 
da Ciência") ${ }^{8}$. Entretanto, em 1930, Elias acabou cancelando esse projeto para seguir a Frankfurt como assistente de Karl Mannheim, sendo que acabou por submeter como tese de habilitação o trabalho intitulado "Der höfische Mensch. Ein Beitrag zur Soziologie des Hofes, der hofischen Gesellschaft und des absoluten Königtums" ("O Homem da Corte. Uma contribuição para a Sociologia da Corte, da Sociedade da Corte e da Monarquia Absolutista"). Este trabalho nunca foi formalmente aceito e acabou sendo publicado apenas em 1969, na Inglaterra, como "Die höfische Gesellschaft. Untersuchungen zur Soziologie des Königtums und der höfischen Aristokratie” ("A Sociedade de Corte: Investigação sobre a sociologia da realeza e da aristocracia de corte") (WAIZBORT, 2001).

Apesar de "O Processo Civilizador" ter sido a primeira publicação de Elias e se tornado também a mais conhecida, "A Sociedade de Corte", como vimos anteriormente, foi a sua primeira obra sociológica. Nessa obra, em seu prefácio, Roger Chartier salienta que Max Weber é um interlocutor privilegiado, sendo que "Wirtschaft und Gesellschaft" ("Economia e Sociedade") é citado por Elias em quatro momentos (CHARTIER, 2001). Embora esta seja a principal obra weberiana referenciada por Elias, existe também em suas obras um forte eco de “A ética protestante e o espírito do capitalismo" (KETTLER; LOADER; MEJA, 2008).

\subsubsection{O salão de Marianne Weber}

Suponho que [Karl Mannheim] deve ter falado de mim com Marianne Weber, e foi assim que um dia fui convidado para o seu salão. Quando se era convidado uma vez para ali, fazia-se parte de seu círculo (ELIAS, 2001a, p. 42).

Para entender minimamente o círculo de intelectuais que já estava constituído quando Elias chegou em Heidelberg em 1924 e, consequentemente, sobre as condições de produção de suas duas obras monográficas, ajuda saber que o impacto de Max Weber sobre a produção sociológica alemã do período ia muito além das repercussões de sua teoria. O círculo em questão possuía um ponto de encontro recorrente, que estava muito longe de ser apenas um espaço físico onde aglomeravam-se alguns indivíduos. Era uma espécie de polo gravitacional, onde todos ali sabiam da fundamental importância de se passar qualquer um que desejasse ser consagrado profissionalmente. Passar por ali simbolizava que os profissionais haviam sido aceitos para fazer parte de um grupo específico, que gozava de certas liberdades e privilégios

\footnotetext{
${ }^{8}$ Cf. Leão e Farias (2012), antes da procura por Alfred Weber, Elias havia tentado habilitar-se em filosofia com Jaspers e este o teria recusado. Em sua obra autobiográfica, Elias (2001a, p. 93) optou por omitir tal informação de sua narrativa.
} 
que eram, em parte, alvo de ambições, em parte, necessários para qualquer sociólogo que almejasse ser reconhecido naquele contexto histórico (ELIAS, 2001a).

À época, apresentar-se no "salão de Marianne Weber" representava o mais alto grau de conhecimento e reconhecimento dos "mandarins" da sociologia alemã. Se Heidelberg era a "Meca da Sociologia", em seu núcleo estava o salão de Marianne. Por ali, circulavam os mais renomados autores do período e também os iniciantes, que aprendiam ali não apenas sobre as produções mais avançadas daquele período em primeira mão, como também as regras e as convenções que guiavam aquele círculo de intelectuais e todos os demais que sustentavam a crença de que ali era o polo central de produção de conhecimento.

Segundo Elias (2001a), a viúva de Max Weber constituía um papel fundamental na manutenção do legado de uma tradição. Naquela época, Max Weber e suas obras ainda não haviam alcançado o seu impacto internacional, porém gozavam de enorme reputação em Heidelberg e na Alemanha de modo geral.

Quando Elias se instalou em Heidelberg, foi alertado por Mannheim que ele deveria receber o aval de Marianne Weber para obter a sua habilitação, mesmo já tendo sido colocado na lista de candidatos por Alfred Weber (ELIAS, 2001a). Marianne ocupava uma posição hierárquica que lhe dava ao mesmo tempo privilégios e responsabilidades importantes naquele círculo de intelectuais, mesmo após o falecimento de Max Weber.

Pouco antes de Elias receber um convite para comparecer à residência de Marianne Weber, Mannheim explicou a Elias que ela tinha uma espécie de salão e que era importante passar por ali qualquer sociólogo que almejasse uma carreira universitária. Lá se reunia periodicamente boa parte da elite universitária de Heidelberg. Elias aceitou o convite de Marianne Weber e apresentou uma exposição sobre a sociologia da arquitetura gótica, falando sobre algumas evidências encontradas nas arquiteturas das catedrais alemãs e francesas. Tais evidências abrigavam elementos que as diferenciavam em termos arquitetônicos, mas também permitiam identificar diferenças estruturais mais amplas, presentes em cada uma dessas sociedades (ELIAS, 2001a).

Marianne, assim como Alfred Weber, pertencia ao universo intelectual alemão da época e ocupava um espaço na sociologia de Heidelberg (ELIAS, 2001a). Era conhecida como uma das mais importantes teóricas dentro da corrente dos estudos feministas na Alemanha em sua época. Porém, por muito tempo Marianne permaneceu em segundo plano, apenas como esposa de Max Weber, em parte porque ela mesma se assumia como tal e via a sua própria obra como inferior a dele. Após a morte de Weber, Marianne passou a se dedicar à 
edição dos trabalhos e correspondências dele, motivada por uma profunda admiração que possuía pelo grande autor da sociologia ${ }^{9}$ (COBO, 1996).

\subsubsection{Norbert Elias e Alfred Weber}

Apesar de Elias ter precisado passar pelo crivo de Marianne Weber para ter o seu ingresso consagrado no círculo de intelectuais de Heidelberg (e, de certa maneira, em toda a sociologia, devido à importância e à centralidade da Universidade de Heidelberg naquele momento histórico para a carreira de sociólogo), Alfred Weber teve também um papel fundamental em sua trajetória profissional.

Segundo Elias (2001a), Alfred Weber assumiu, em parte, a sucessão de Max Weber na sociologia, porém ele fez isso à sua maneira. Alfred possuía especial interesse na "cultura", sendo que a via como o elemento fundamental para compreender qualquer sociedade e incomodava-se, particularmente, com o fato de alguns autores a reduzirem em explicações estritamente econômicas. Para o irmão de Max Weber, as produções [Gebilde] humanas de cultura diferenciavam-se substancialmente daquelas produções de caráter utilitário - tais como a ciência, a técnica e a economia -, sendo que as primeiras expressariam o espírito de uma época em um plano simbólico. As pesquisas de Alfred Weber retomavam e também avançavam, sobretudo, na antiga díade alemã "cultura" e "civilização"10.

Elias (2001a) argumentou que o conceito de "cultura" que encontrou em Alfred Weber possuía a significação de um símbolo sentimental, apesar de estar amparado em fatos objetivos. Elias via nos escritos de Alfred Weber uma postura partidária bem mais apaixonada do que em Max Weber, o qual não se permitia tal postura e devido a isso também se deveu a perenidade dos seus trabalhos. Em linhas gerais, as produções de Alfred Weber eram marcadas pela cultura apresentada com alto valor e a civilização como algo de importância menor.

O principal adversário de Alfred Weber não estava nos partidos ou nos movimentos de esquerda, mas sim encontrava-se na figura que representava, na visão dele, alguém que defendia tudo de mais utilitário, Karl Mannheim (ELIAS, 2001a). Havia um conflito em jogo que incluía também divergências político-partidárias. Alfred Weber era um declarado liberalconservador e Karl Mannheim possuía simpatias políticas em direção a uma esquerda

\footnotetext{
${ }^{9}$ Um dos principais frutos desta empreitada de Marianne Weber (1926) foi a publicação de sua obra Max Weber. Ein Lebensbild, traduzida para o português como "Max Weber. Uma biografia".

${ }^{10}$ Essa discussão pode ser encontrada de forma mais aprofundada em Elias (1994).
} 
moderada - e que se manifestava, sobretudo, nos postulados sociológicos elaborados por estes dois autores. Nessa "guerra fria":

Como Privat-dozent, Mannheim tinha visivelmente menos poder e prestígio que Alfred Weber, que era professor titular. Mas inúmeras pessoas viam nele o homem do futuro, a estrela em ascensão da sociologia de Heidelberg. Embora tenha participado tanto dos seminários de Karl Mannheim como dos de Alfred Weber, a princípio eu não percebia nada da rivalidade semeada entre esses dois homens. Um tom bastante moderado era então de rigor nas relações humanas na Universidade de Heidelberg. Nas declarações que faziam um sobre o outro, a julgar pelas que presenciei, Weber e Mannheim se mostravam extremamente prudentes. Portanto, foi uma grande surpresa quando a rivalidade dos dois homens explodiu abertamente. Foi durante o VI Congresso de Sociologia Alemã, em Zurique (ELIAS, 2001a, p. 123).

Lembrando aqui da análise feita por Elias sobre o conflito entre Drake e Doughty em Estudos sobre a gênese da profissão naval, o conflito entre dois seres humanos "por mais que possa ser algo único e pessoal, pode ser ao mesmo tempo representativo de uma luta entre diversos estratos sociais, remontando a várias gerações" (ELIAS, 2006, p. 70). Em uma análise que supera uma visão estritamente micro ou macrossociológica, na sociologia relacional de Elias, na qual o que é "social" é também “individual” e o que é "individual” é também "social”, é possível entender a partir do conflito entre Drake e Doughty, mas também entre Alfred Weber e Karl Mannheim, aspectos mais amplos da rede de relações pela qual estes indivíduos encontravam-se conectados.

O conflito entre Karl Mannheim e Alfred Weber ajuda-nos a compreender, portanto, um pouco do que se passava naquele círculo de "mandarins" da sociologia alemã, algumas possíveis motivações para a elaboração de suas teorias. É possível entender que tais intelectuais, mesmo fazendo parte de uma mesma figuração ${ }^{11}$, estavam engendrados em uma rede de relações na qual havia uma pluralidade de interesses e, ao mesmo tempo, objetivos em comum, como o de demarcar posições frente a outros intelectuais naquele campo de disputas pelo próprio reconhecimento profissional (ELIAS, 2001a). Dessa forma, tal como em outras figurações, o círculo de intelectuais de Heidelberg estava marcado, nos termos de Elias, por um equilíbrio móvel de tensões.

\footnotetext{
${ }^{11}$ Termo cunhado por Elias (2001b) para designar uma teia simbólica de indivíduos conectados de modo interdependente.
} 


\section{De Heidelberg a Frankfurt}

Norbert Elias foi contemporâneo de uma geração de sociólogos alemães que adquiriram fama internacional antes da Segunda Guerra: Karl Mannheim, Walter Benjamin, Max Horkheimer e Theodor Adorno (WEILER, 1998). Foi em 1930 que Karl Mannheim partiu de Heidelberg para preencher uma cadeira em Frankfurt, sendo que convidou Elias para segui-lo e auxiliá-lo em sua trajetória.

Em Frankfurt, Elias assumiu o seu trabalho no Soziologisches Seminar (Seminário de Sociologia), o qual era dirigido por Mannheim e ficava no primeiro andar do Institut für Sozialforschung (Instituto para Investigação Social), sob a direção de Max Horkheimer. Este parecia a Mannheim "muito de esquerda", sendo que Mannheim para Horkheimer lhe aparentava "muito de direita". Nesse contexto, os seus dois assistentes, Norbert Elias e Leo Lowenthal, atuavam como intermediários (KORTE, 1998).

Em Frankfurt, Elias teve um papel único excepcional na constituição do grupo de Mannheim e em suas produções acadêmicas. Assim, instaurou-se não apenas uma "influência" de Mannheim em Elias, mas uma via de mão dupla, marcada por uma "influência" recíproca entre os dois autores (KETTLER; LOADER; MEJA, 2008).

Conforme destacaram Leão e Farias (2012), Elias chegou em Frankfurt em um momento propício para o desenvolvimento de trabalhos comparativos e interdisciplinares que articulavam, entre outras disciplinas, a psicologia, a sociologia e a história. Tal característica veio a se tornar marcante em suas obras.

Pouco tempo antes de Elias chegar à cidade, em 1929, havia sido fundado o Frankfurter Psychoanalytische Institut (Instituto de Psicanálise de Frankfurt - FPI, na sigla em alemão). Ao longo de seu próprio processo de formação, teria ocorrido uma aproximação da Escola de Frankfurt com o que foi nomeado de "freudismo", 12 tornando-se uma característica comum nas produções de seus membros (ASSOUN, 1991a; 1991b). Todo esse contexto pode ter sido responsável pela grande aproximação de Elias com os estudos de Freud nesse período. Segundo Leão e Farias (2012), além da aproximação intensa do "jovem Elias" da psicanálise freudiana, foi também em Frankfurt, já em um movimento posterior de afastamento de Freud (devido aos seus postulados de estruturas universais do psiquismo

\footnotetext{
${ }^{12}$ Conforme Assoun (1991b, p. 7), o freudismo pode ser denominado como "aquilo que impede a psicanálise de se reduzir a si mesma, à sua própria objetividade".
} 
humano $)^{13}$, que Elias teria também entrado em contato com outros trabalhos de base psicológica, notadamente os de Jean Piaget e Heinz Werner.

\subsection{Norbert Elias e sua relação com Karl Mannheim}

- E lá [em Heidelberg] Mannheim era sua referência intelectual mais importante?

- É um pouco difícil dizer, pois em muitos pontos não concordava com ele. Não, falar de referência intelectual seria exagerado (ELIAS, 2001a, p. 47).

Karl Mannheim pode ser considerado um dos merecedores de maior destaque dentro dessa rede de relações, que teria repercutido em grande medida na formação e na trajetória de Norbert Elias. Além da grande admiração que Elias mantinha por Mannheim, ele encontrou em sua figura um grande amigo, amizade que apenas iniciou em Heidelberg e perdurou durante muitos anos, mesmo após Elias começar a divergir de alguns de seus postulados sociológicos. Além disso, em uma leitura atenta às obras de Elias é possível perceber suas influências não apenas em termos de suas "ideias flutuantes", mas também em termos de posicionamentos importantes frente ao círculo de intelectuais onde ambos estavam inseridos e a características específicas da produção acadêmica tradicional que vigorava na época.

Elias conheceu Karl Mannheim em Heidelberg onde este, segundo o próprio Elias afirmou, encontrava-se no auge de sua produção intelectual. Foi em 1924 que Mannheim escreveu "Ideologia e Utopia", uma de suas principais obras, além de outros ensaios, entre os quais o que abordava sobre a "significação da competição no domínio intelectual" que, conforme Elias (2001a), constituía um problema pessoal para Mannheim.

Segundo Elias (2001a), Mannheim concentrou-se em um aspecto específico da teoria de Karl Marx e dela fez o seu domínio de conhecimento: a sociologia do conhecimento. Esta área posteriormente tornou-se o que hoje se conhece como Sociologia da Cultura. Muitos aspectos teóricos aproximavam Mannheim de Elias, porém houve um momento em que Elias questionou muitos de seus posicionamentos, distanciando-se de sua linha teórica.

Talvez um papel muito importante que Mannheim tenha exercido no pensamento de Elias foi o de passar a própria inquietação que ele tinha a respeito do modo tradicional como era concebida a produção intelectual até aquele momento. De acordo com Elias (2001a),

\footnotetext{
${ }^{13}$ Cf. Lahire (2013), Elias tece uma de suas principais críticas a Freud por meio do conceito de "valência". Ao reduzir tudo a pulsões sexuais, Freud não haveria considerado a pluralidade de valências que seria possível aos indivíduos. Além disso, Elias (2010) afirma que Freud teria conferido valor universal a um tipo dado e datado de estruturas de personalidade, que estendeu a todos os seres humanos.
} 
Mannheim teve vital importância para repensar aqueles padrões, na medida em que argumentava no sentido de que uma produção intelectual não deveria ser vista como apenas "pensamentos" ou "ideias" flutuantes no espaço, mas sim que era sempre resultante de demarcações de posições sociais específicas, de competições entre pesquisadores. Influenciado pela tese marxista de que o pensamento não está apenas ligado a interesses, mas sim que o é necessariamente, Mannheim (e também Karl Marx) suscita a ideia dualista de um "ser" social desprovido de pensamento, em quem este aparece apenas como um anexo. Para Elias (2001a), tanto Mannheim como Marx pecaram no sentido de não levarem em conta em suas formulações o fato de que a consciência e o pensamento são, na verdade, constitutivos da sociedade.

Para além dos detalhes desta formulação de Mannheim, que não são o foco da análise aqui empreendida, vemos aqui o que parece ter sido uma de suas importantes implicações no pensamento eliasiano - a de questionar a maneira como toda uma tradição acadêmica, em especial aquela que inclui as ciências humanas e a história das ideias, lidava com determinadas noções, tais como a de "espírito", "ideias" e "pensamentos". Tais noções davam a entender que era possível que existissem "produções flutuando livremente", vistas de modo dissociado e independente da vida em sociedade.

Novamente, na esteira e ainda mais radical do que Marx, Mannheim postulou que todas as ideias (e também as de Marx e as suas próprias) deviam ser "ligadas ao ser", como a expressão de uma posição nas lutas sociais e esta, necessariamente, limitava a visão dos autores sobre as coisas (ELIAS, 2001a). Esta noção é pano de fundo para o forte posicionamento posterior de Elias de que as ideias ou pensamentos, na medida em que não existem por si próprios, não podem aparecer desvinculados de seu contexto de produção, no qual tem importância vital o conhecimento da posição social dos seus produtores. Para fugir do total relativismo que culminaria se levássemos até o fim desse raciocínio - onde qualquer esforço de pensamento dos indivíduos seria condenado -, Mannheim criou o conceito de "relacionismo" [Relationismus]. Nessa concepção, além do fato de que qualquer pensamento deve ser visto "ligado ao ser", os indivíduos têm olhares parciais sobre o mundo, principalmente quando situados em diferentes posições de classe (ELIAS, 2001a).

De Heidelberg a Frankfurt, Elias (2001a) narrou a parte de sua trajetória com Mannheim como sempre "muito agradável" e "praticamente sem atritos". Foi durante esse itinerário, marcado por uma fidelidade a Mannheim e que culminava em Frankfurt, que Elias teria feito a descoberta de uma missão, a qual deveria desenvolver enquanto sociólogo: 
Foi pouco a pouco que compreendi essa missão, de maneira ainda bastante vaga durante minha temporada em Heidelberg, depois de modo mais nítido em Frankfurt. Ela consistia em elaborar uma teoria central da sociologia que fosse empírica, ou seja, verificável e emendável, em vez de fundar as bases de uma teoria sobre as quais as gerações futuras pudessem construir, ou mesmo rejeitar, corrigir e desenvolver. Mergulhei nessa consciência cada vez mais aguda de meus objetivos e trabalho nisso até hoje, entremeado às numerosas tarefas particulares que realizei ao longo de minha vida (ELIAS, 2001a, p. 145).

A versão original de "A Sociedade de Corte", uma de suas principais obras, foi escrita como tese de habilitação em Frankfurt. Apesar disso, a versão publicada em 1969 não é idêntica à original submetida como tese de habilitação, que estava aos cuidados de Mannheim. Alguns capítulos foram acrescentados a partir de 1966, quando Elias conseguiu recuperar o seu escrito original (perda esta ocorrida em virtude do nazismo), notadamente uma longa introdução metodológica, baseada na reconceitualização de Elias sobre uma conjunção entre história e sociologia, assim como comentários que parecem derivar dessa mesma revisão. Apesar disso, os capítulos principais não sofreram alterações substanciais, portanto a análise original feita por Elias não teve grandes transformações a partir das novas reflexões (KETTLER; LOADER; MEJA, 2008).

O capítulo "Estruturas de habitação como indicadores de estruturas sociais" foi publicado de modo idêntico ao texto original escrito em 1933. O conteúdo abordado por Elias nesse capítulo estava alinhado ao grupo de pesquisa de Mannheim, sendo que o estilo da narrativa era típico daquele momento histórico. Tudo começou quando a Revue Internationale de Sociologie de janeiro de 1932 anunciou Mannheim como colaborador da seção " $L$ 'habitat humaine" no Congresso do Institute Internationale de Sociologie em Geneva, com a apresentação de "The human habitat from the perspective of the social role of woman and the domestic economy" ("O habitat humano a partir da perspectiva do papel social da mulher e da economia doméstica"). Mannheim, não podendo comparecer, elegeu dois substitutos para ir em seu lugar, Margarete Freudenthal e Norbert Elias (KETTLER; LOADER; MEJA, 2008).

Apesar de os dois pesquisadores divergirem em suas apresentações, mostraram como o grupo de pesquisa de Mannheim, apesar de seguir em direções diferentes, não perdia pontos de referência em comum. Ambos procuravam explicar "correlações entre tipos de casas e níveis de existência social" de seus habitantes. Elias tratava das casas dos cortesãos franceses nos séculos XVII e XVIII, em linhas gerais, identificando que a residência era constituída a partir do posto e da função de seus proprietários e que estava vinculada a aspectos dos estilos de vida - como as relações de hospitalidade recíproca e as necessidades de luxo, de uma 
equipe de funcionários e de coabitação. Já Freudenthal contrastava casas de proletários e de burgueses, em referência às suas respectivas economias domésticas, argumentando no sentido de que o modo da existência material variava conforme o papel econômico da mulher, tanto dentro como fora das residências (KETTLER; LOADER; MEJA, 2008).

Portanto, havia um certo alinhamento entre as pesquisas de Elias e Freudenthal com as de Mannheim e seu grupo, porém a produção de Elias se distanciou em muitos aspectos do que Mannheim propunha. Conforme Kettler, Loader e Meja (2008), a postura não impositiva que Mannheim manteve com Elias pode ter sido inspirada em seu respeito a Alfred Weber, lembrada no septuagésimo aniversário deste por Mannheim:

When a philosopher with a long beard [presumably Heinrich Rickert] wanted to force me, year after year, to think as he did, and when I then came to you to submit my work, I was struck by the fear that you would similarly control whether my thoughts reproduced yours. Then you said, to my great surprise: "I will read your work, but it has already been accepted, for you are an adult and must say what you think right." These sentences have had a lasting impact on me. It is only because of this experience that I overcame, from the outset, the teacher's dangerous inclination to attempt to form students in his own image. This attitude of yours is, however, simultaneously the explanation for the fact that you have spiritually independent students everywhere in the world, who, though they will always declare themselves for you in the depths of their souls, are much too independent to form a school in the usual sense, one that fights for one-sided principles or appears self-enclosed like a sect, unified by a dogma (MANNHEIM, 2001 apud KETTLER; LOADER; MEJA, 2008, p.77).

\section{Considerações finais}

A rede de relações na qual Norbert Elias foi imerso em sua chegada a Heidelberg foi decisiva para a sua formação sociológica, para a elaboração de suas principais obras e também para o seu reconhecimento, mesmo que tardio. O "espírito" e o círculo de weberianos inaugurados e intensificados imediatamente após o falecimento de Max Weber repercutiram amplamente nas tomadas de posição de Elias enquanto autor de uma teoria social própria. Podemos compreender com maior clareza, quando o inserimos dentro dessa figuração específica, os seus posicionamentos presentes tanto em sua autobiografia como também em suas demais obras.

Mesmo com as particularidades de cada autor, muitos elementos eram compartilhados nas produções advindas daquele círculo de "mandarins" da sociologia alemã. Características comuns puderam ser evidenciadas, por esta e por outras pesquisas, em termos de narrativa, 
relativas à forma, como as questões de estilo, e ao conteúdo, a exemplo da escrita do capítulo "Estruturas de habitação como indicadores de estruturas sociais" de "A Sociedade de Corte", na qual o conteúdo encontrava-se alinhado ao grupo de Karl Mannheim, além do fato de que o estilo da narrativa era típico daquele momento histórico.

As narrativas daqueles autores também possuíam em comum os impactos da conjuntura política e cultural do período, vigente no momento em que Elias chegou a Heidelberg. Em virtude do clima de "crise da cultura" na Alemanha, era frequente que os autores se posicionassem em termos de uma preocupação com o ensino e com a vida cultural alemães, algo que se tornou habitual na construção do legado "mandarim". Além disso, era muito difícil o nazismo não impactar de alguma maneira naquelas narrativas.

Pelas diversas razões que apontamos ao longo desse artigo, a passagem de Elias pelas duas cidades, Heidelberg e Frankfurt, constituiu em uma fase-chave de sua trajetória intelectual, impactando de forma decisiva em sua formação e na sua inserção no círculo de sociólogos renomados do período. Devido ao ambiente intelectual de Heidelberg, era quase impossível que nas suas obras e de seus contemporâneos não emergissem temas weberianos. Entretanto, mesmo inserindo-se no "mundo de Weber", talvez em seu momento de maior efervescência, Elias não veio a ser tornar um "weberiano". Além disso, foi em Frankfurt, como assistente de Mannheim, que Elias veio a fortalecer o seu viés freudiano, central e norteador de suas duas principais obras, "A Sociedade de Corte" e "O processo civilizador". 


\section{Referências}

ASSOUN, Paul-Laurent. A Escola de Frankfurt. São Paulo: Editora Ética, 1991a. . O Freudismo. Rio de Janeiro: Jorge Zahar Editor, 1991 b.

BEAUVOIR, Simone. Os mandarins. Rio de Janeiro: Ed. Nova Fronteira, 1983.

BOURDIEU, Pierre. A ilusão biográfica. Razões Práticas: sobre a teoria da ação. Campinas: Papirus, 1996.

BREUER, Stefan. Society of individuals, society of organizations: a comparison of Norbert Elias and Max Weber. History of the human sciences, vol. 7, n 4, pp. 41-60, 1994.

BUCHOLC, Marta. Irony as vocation: the fate of a social scientist in the writings of Max Weber and Norbert Elias. In: DÉPELTEAU, F.; LANDINI, T. S. (orgs.). Norbert Elias and Social Theory. New York: Ed. Palgrave Macmillan, 2013.

CHARTIER, Roger. Prefácio. In: ELIAS, N. A sociedade de corte: investigação sobre a sociologia da realeza e da aristocracia de corte. Rio de Janeiro: Jorge Zahar Editor, 2001.

COBO, Rosa. Marianne Weber: Max Weber. Una biografía, Rev. Sociológica, 1: 181-185, 1996.

COMBESSIE, Jean-Claude. O método em sociologia. São Paulo: Edições Loyola, 2004.

DARNTON, Robert. O beijo de Lamourette. Mídia, cultura e revolução. Tradução de Denise Bottmann. São Paulo: Companhia das Letras, 1990.

DUNN, John. The Identity of the History of Ideas. Philosophy, vol. XLIII, no 134, pp. 85104, 1968.

ELIAS, Norbert. O processo civilizador: uma história dos costumes. 2. ed. Vol. 1. Rio de Janeiro: Jorge Zahar Editor, 1994.

. Norbert Elias por ele mesmo. Rio de Janeiro: Jorge Zahar Editor, 2001a.

- A sociedade de corte: investigação sobre a sociologia da realeza e da aristocracia de corte. Rio de Janeiro: Jorge Zahar Editor, 2001b.

Editor, 2006.

Escritos \& ensaios: 1- Estado, processo, opinião pública. Rio de Janeiro: Jorge Zahar

- Au-delà de Freud: Sociologie, Psychologie, Psychoanalyse. Paris: Éditions la Découverte, Laboratoire des sciences sociales, 2010.

HEINICH, Nathalie. A Sociologia de Norbert Elias. São Paulo: EDUSC, 2001.

JOLY, Marc. Devenir Norbert Elias: histoire croisée d'un processus de reconnaissance scientifique: la réception française. Paris: Librairie Arthème Fayard, 2012. 
KETTLER, David; LOADER, Colin; MEJA, Volker. Norbert Elias and the Sociology of External Forms. In: KETTLER, D.; LOADER, C.; MEJA, V. (orgs.). Karl Mannheim and the legacy of Max Weber: Retrieving a Research Programme. Burlington: Ashgate, 2008.

KORTE, Hermann. Mirada sobre una larga vida: Norbert Elias y la teoría de la civilización. In: WEILER, Vera. Norbert Elias: La Civilización de los Padres y Otros Ensayos. Bogotá: Grupo Editorial Norma, 1998.

KRIEKEN, Robert Van. Norbert Elias and Process Sociology. In: RITZER, G.; SMART, B. (orgs.). Handbook of Social Theory. London: Sage Publications, 2001.

LACROIX, Bernard. Portrait sociologique de l'auteur. In: GARRIGOU, Alain; LACROIX, Bernard (orgs.). Norbert Elias: la politique et l'histoire. Paris: La Découverte, 1997.

LAHIRE, Bernard. Elias, Freud, and the Human Science. In: DÉPELTEAU, F.; LANDINI, T. S. (org.). Norbert Elias and Social Theory. New York: Ed. Palgrave Macmillan, 2013.

LEÃO, Andréa Borges; FARIAS, Edson. Apresentação. Dossiê: Reinventar Norbert Elias. Soc. Estado, Brasília, v. 27, n. 3, pp. 458-468, 2012.

MICELI, Sérgio. Biografia e Cooptação (o estado atual das fontes para a história social e política das elites no Brasil). Intelectuais à Brasileira. São Paulo, Companhia das Letras, pp. 345-356, 2001.

POCOCK, John. The History of Political Thought: A Methodological Enquiry. In: LASlETT, P.; RUNCIMAN, W. G. (eds.). Philosophy, Politics and Society. Oxford: Blackwell, pp. 183-202, 1962.

PONTES, Heloisa. Círculos de intelectuais e experiência social. Revista Brasileira de Ciências Sociais, São Paulo, ANPOCS, vol. 12, n. 34, junho, pp. 57-69, 1997.

RINGER, Fritz. O declínio dos mandarins alemães: a comunidade acadêmica alemã, 18901933. São Paulo: Edusp, 2000.

. A metodologia de Max Weber: a unificação das ciências culturais e sociais. São Paulo: Edusp, 2004.

ROTMAN, David. «Trajectoire intellectuelle et expérience du camp : Norbert Elias à l'île de Man », Revue d'histoire moderne et contemporaine, vol. 52-2, no. 2, pp. 148-168, 2005.

SKINNER, Quentin. Meaning and Understanding in the History of Ideas, History and Theory, vol. 8, no 3, pp. 3-53, 1969.

SILVA, Ricardo. O contextualismo linguístico na história do pensamento político: Quentin Skinner e o debate metodológico contemporâneo. DADOS - Revista de Ciências Sociais, Rio de Janeiro, vol. 53, n.2, pp. 299-335, 2010. 
TREIBER, Hubert; SAUERLAND, Karol (org.). Heidelberg im Schnittpunkt intellektueller kreise: Zur Topographie Der Geistigen Geselligkeit" Eines Weltdorfes": 1850-1950. Opladen: Westdt. Verl, 1995.

WAIZBORT, Leopoldo. Apresentação. In: NEIBURG, F.; PONTES, H.; SOUZA, J.; WAIZBORT, L.; MICELI, S. (orgs.). Dossiê Norbert Elias. 2. ed. São Paulo: Edusp, 2001.

WEBER, Alfred. Die Bedeutung der geistigen Führer in Deutschland, Die neue Rundschau, Berlin, 29: 1249-1268, 1918.

WEBER, Marianne. Max Weber. Ein Lebensbild. Mohr: Tübingen, 1926.

WEILER, Vera. Presentación. In: WEILER, Vera. Norbert Elias: La Civilización de los Padres y Otros Ensayos. Bogotá: Grupo Editorial Norma, 1998.

Recebido em 09-06-2017;

Revisado em 17-04-2018;

Publicação em 15-12-2018. 